\title{
Evaluation of Reconfigurability in Brownfield Manufacturing Development
}

\author{
Simon BOLDT ${ }^{\mathrm{a}, 1}$ and Carin RÖSIÖ̈ \\ a Department of Industrial Product Development, Production, and Design, School of \\ Engineering, Jönköping University, Sweden
}

\begin{abstract}
To enable manufacturing firms adapting their manufacturing capabilities to meet the market demands in a cost-efficient way the concept of reconfigurable manufacturing was initiated. A majority of the research within this field targeting production development has been focused on greenfield development methods, enabling the developers to ignore context and constraints that brownfield development methods cannot. The greenfield focus in reconfigurability research has resulted in how to find optimal solutions to reconfiguration problems. Taking a brownfield focus on reconfigurable manufacturing development would enable to move step-by-step towards a reconfigurable manufacturing strategy instead of the all-or-nothing approach of greenfield development methods. This study investigates through a literature review what assessment tools and methods that exists in literature, and classifies them into four categories, i.e. Configuration evaluation, Element of evaluation, Pre-design evaluation, and Potential evaluation. It is found that there only exist two assessment tools for potential evaluation. Through a multiple case study, the potential evaluation process is evaluated, and three gaps is identified, i.e. lack of connection to strategy, lack of predefined goals for reconfigurability, and the difficulty in interpreting the result of the analysis. These gaps are then address in a new conceptual assessment process for assessing the potential of reconfigurability. The conceptual assessment process links the six reconfigurability characteristics throughout the whole assessment process to link manufacturing strategy to the improvement suggestions.
\end{abstract}

Keywords. Reconfigurability, RMS, Evaluation tool, Assessment tool, Brownfield manufacturing

\section{Introduction}

To efficiently handle ever changing market demands within manufacturing system design, the concept of reconfigurable manufacturing was initiated by Koren et al. [1] in the late 90's. Reconfigurable manufacturing, as a part of the umbrella term changeable manufacturing, has since then become widely recognised as the manufacturing paradigm of the future [2]-[4]. A reconfigurable manufacturing system possesses the capabilities to repeatedly adapt and change its manufacturing elements in a cost-efficient way to ensure readiness to meet new market and technological requirements [5]-[7].

Even though reconfigurable manufacturing is deemed to be the next manufacturing paradigm there are few success stories of reconfigurable manufacturing systems

\footnotetext{
${ }^{1}$ Corresponding author. simon.boldt@ju.se
} 
implemented in industry [5], [8]. With the promising concept and what it entails, it can be concluded that implementation barriers for industry exist. Sorensen, Brunoe, \& Nielsen [9] argue that reason for why industrial companies have been reluctant to leave their old ways of designing manufacturing systems and implement reconfigurable manufacturing is that the main part of the research regarding reconfigurability is made through greenfield development [8], [10]. Greenfield development enables the developer to ignore the existing manufacturing context and constrains and, thus, limits the majority of the potential industry candidates. To reduce the barrier of moving towards reconfigurable manufacturing a brownfield development approach needs to be applied.

Several challenges have, however, been identified in reconfigurable development in a brownfield context. Primarily, reconfigurability knowledge and skills in order to satisfy the need for change in terms of the type and the extent of reconfigurability is missing as well as a long-term plan towards reconfigurability [11]. In order to transform a manufacturing system and increase the level of reconfigurability it is crucial to formulate a strategy with long-term goals [12], [13] and be able to understand and assess the existing performance of the system and its change potential [10], [14], [15]. An assessment tool for reconfigurable manufacturing enables the manufacturing firm to understand the current level of reconfigurability within their manufacturing system [16]. This requires mapping of the existing manufacturing system based on reconfigurability characteristics [17]. Although there are a several reconfigurability assessment tools available [7], [16], [18], [19], they provide limited support to manufacturing industry for reconfigurability development in a brownfield development context. Existing methods often focusing finding the optimal configuration in a given manufacturing system or justifying the concept of reconfigurability against other design concepts such as flexible or dedicated manufacturing solutions. Moreover, existing models are seldom described in the context where it will be applied. Consequently, there is a knowledge gap in how to assess existing manufacturing system based on reconfigurability characteristics but also in the assessment process describing how to use the assessment tools as a support for reconfigurable manufacturing system development.

The purpose of this paper is, therefore, to increase the knowledge of the transformation towards reconfigurable manufacturing systems in a brownfield context by development of a conceptual assessment process.

In order to fulfil the purpose two research questions (RQ)s have been created. RQ 1: What are the current existing assessment tools and methods available in literature for assessing reconfigurability? RQ 2: How could the potential for reconfigurability be assessed in existing manufacturing systems?

In the following paper the state of art is presented including the gaps of current existing assessment tools. Combined with the results of a multiple case study a conceptual assessment process for reconfigurability is developed for brownfield manufacturing systems.

\section{Method}

A literature review was conducted (based on [20]) in order to review existing assessment methods and tools to identify a research gap, that the potential of reconfigurability within a manufacturing system is not considered, and serve as input to the development of a conceptual assessment process. The Scopus database was used for the literature search were scientific journal papers and conference papers were included. The selection 
strategy for the literature consist of four tiers, the first tier, the exclusions done based on the article title, second tier, exclusion done by reading through the abstract, the third exclusion were done through the accessibility of the research paper through the university licences, and the fourth tier was done through reading the full paper. Backward and forward citing was also used to include interesting literature leads. The result of the literature review can be viewed in Table 1 .

Table 1. Literature review result

\begin{tabular}{cccccccc}
\hline Search terms & $\begin{array}{c}\text { Initial } \\
\text { result }\end{array}$ & Tier 1 & Tier 2 & Tier 3 & $\begin{array}{c}\text { Tier 4 } \\
\text { Backward/ } \\
\text { forward }\end{array}$ & Total \\
\hline $\begin{array}{c}\text { (Reconfig* OR RMS) } \\
\text { AND (Manufacturing or }\end{array}$ & 371 & 28 & 23 & 18 & 16 & 6 & 22 \\
$\begin{array}{c}\text { Production) AND } \\
\text { Assessment }\end{array}$ & & & & & & & \\
\hline
\end{tabular}

The clustering of the research papers was done through open coding to give a general overview of the assessment methods being used in the research field.

In order to increase the knowledge of the transformation towards reconfigurable manufacturing systems in a brownfield context an assessment tool for assessing the potential for reconfigurability was chosen, see [21]. The assessment tool is a excel based tool included questions analysing the reconfigurability characteristics of both quantitative and quantitative character. The tool required that the questions are answered by practitioners with deep knowledge of their manufacturing processes. In this study the usage of the tool, i.e. the process of assessing the potential for reconfigurability has been studied.

The assessment process was studied in a multiple case study [22] including four cases. In each of the cases manufacturing sub-systems were identified as potential areas for an increased level of reconfigurability. The reconfigurability of these areas were assessed with the assessment tool and, thereafter, conceptual reconfigurable solutions were developed.

The unit of analysis was the process of reaching the reconfigurable conceptual solutions and the activities carried out to reach these conclusions. All cases where carried out in global, large industrial companies. The subsystems that were assessed where all located in manufacturing sites in Sweden.

The empirical data was collected by document studies and observations of the assessment process. The development teams conducting the assessments included production engineers, production developers, project managers, production planner and production managers. Observations were carried out three times in each case including meetings where the assessment activities were carried out. Both the documents that were used as well as generated in the assessment process (except the assessment tool) were studied. The documents included strategy documents, planning documents and conceptual design ideas.

The data from the literature review and the empirical data were categorized into main activities and process steps. Based on the results of the case study and the literature review a conceptual assessment process was synthesized. 


\section{Theory}

\subsection{Assessment tools}

There exist several tools for justification, evaluation, and assessment for different aspects of reconfigurability, an overview of the methods and tools found through the literature review is presented in the following section.

Prasad and Jayswal [23] presented a configuration tool for part family selection through the use of a similarity index, average linkage cluster (ALC) algorithm, and measures for reconfiguration effort. Andersen, Brunoe, Nielsen, and Bejlegaard [24] evaluated configuration of reconfigurable manufacturing system during the concept phase through economical evaluation to provide decision support. Haddou Benderbal, Dahne, and Bentoucef [25] assessed different configuration to find the optimal configuration based on the modularity of the system. Park [26] evaluated different configurations through a design structure matrix (DSM) and used analytical hierarchical process (AHP) to create weighted criteria, the criteria were grouped into structural and economical key performance indicators (KPIs). Eguía, Villa, and Lozano [27] evaluated the manufacturing system's efficiency to be able to choose the best configuration for the system. Urbanic and Hedrick [28] created a decision support model where they evaluated different configurations of the manufacturing system in aspect to the process complexity, key attributes (transitional complexity) and key resources (time element and financial element). Farid [29] assessed different configurations through how easy the manufacturing system could be reconfigured, by measuring modularity i.e. number of interfaces between modules, complexity of seperating modules, and complexity of reconnecting modules. Youssef and ElMaraghy [30] created a configuration selection method through the assessment of reconfiguration smoothness i.e. assessing the smoothness on three different levels market-level, system-level, and machine-level. Bellini, Bounopane, and Nesi [31] created an optimal configuration assessment method for CNC-pipelines (multiple connected CNC-machines) which had distributed control. Wang, Huang, Yan, and $\mathrm{Du}$ [32] ranked different configurations based on their evaluation index which used the key characteristics of reconfigurability through the method of preference ranking organization method for enrichment evaluation (PROMETHEE) and AHP for weights of the characteristics. Putik, Telgen, van Morgestel, and Ceglarek [33] investigated how different configurations in the manufacturing system could be evaluated through the use of axiomatic index methodology with the assessment criteria of resources and lead time. Singh et al. [19] presented a decision support system based on a fuzzy-AHP with multi-person, multiperiod, and multi-criteria, which evaluated configurations of the manufacturing system through subjective key characteristics (i.e. ramp-up time, modularity, responsiveness, interface, and complexity) and objective key characteristics (i.e. cost). Abdi, Labib, and Ashraf [34] presented a justification method for selection of different configurations through economical and operational feasibility. Rösiö, Aslam, Srikanth, and Shetty [35] presented a qualitative evaluation tool, which assessed the reconfigurability of a manufacturing system through the fulfilment of each key characteristic of reconfigurability. Bergström and Jödicke [21] then further developed the evaluation tool and its level of detail by going further in-depth in how each of the key characteristic could be assessed. Pattanik et al. [18] created an assessment tool for the need of reconfigurability based on the capacity needed in current and future manufacturing system using a fuzzy demand set. Schun et al. [36] investigated the economics of scale 
and economic of scope dilemma and present an assessment method based on four categories, product program, product architecture, production, and supply chain, to find the efficient frontier in the scale-scope dilemma. Farid and McFarlane [37] assessed the degree of freedom in a manufacturing system through the use of axiomatic design and holonomic constraints to measure the potential in a manufacturing system to be reconfigurable. Farid and McFarlane [14] investigated the potential of reconfigurability with a DSM method as an assessment tool manufacturing systems within distributed control by assessing modularity, integrability, diagnosability, convertibility, and customisation, which were suggested to be used together with the systematic work method developed by Farid and McFarlane [38]. Abdi et al. [7] created a design strategy where they created strategic criteria for reconfigurability which then were used for strategic justification for reconfigurable manufacturing.

The assessment tools and methods are summarised and presented in Table 2, where they are clustered according to the character of the assessment tool or method. The first group, configuration evaluation, has the largest focus in the found literature. These methods and tools focus on the selection between different configurations of an existing manufacturing system. The configuration evaluations methods and tools have the assumption that the manufacturing system being evaluated already can reconfigure itself. The second group, element of evaluation, are elements of a reconfigurability evaluation e.g. how to measure modularity [29] or the scale-scope trade-off [36]. The third group, pre-design evaluation, are methods and tools which focuses on the evaluation of the concept of reconfigurability over other designs concepts e.g. flexible manufacturing. The pre-design evaluations do often justify reconfigurability from both an economical and a feasibility perspective. The fourth group, potential evaluation, evaluates the reconfigurability potential in the manufacturing system and provides improvement areas within for the manufacturing system to increase the existing manufacturing systems reconfigurability level.

Table 2. Assessment methods and tools

\begin{tabular}{lll}
\hline$\#$ & Classification & Author \\
\hline 1 & Configuration evaluation & {$[17],[23],[25]-[28],[31]-[34]$} \\
2 & Element of evaluation & {$[14],[18],[29],[30],[36]-[38]$} \\
3 & Pre-design evaluation & {$[7],[19],[34],[39]$} \\
4 & Potential evaluation & {$[21],[35]$} \\
\hline
\end{tabular}

The literature review answers RQ 1 by showing that the focus of research has been on the selection of different configurations in an already reconfigurable manufacturing system, and the evaluation of the reconfigurability concept. Different evaluation elements have also gotten some attention. However little focus has been given to the development of reconfigurability in a brownfield context, where the capabilities that are necessary to become reconfigurable should be evaluated to find improvement areas for step-by-step improvement implementation. The two assessment tools for evaluating current potential for reconfigurability in the manufacturing system, i.e. [35] and [21], are however, lacking the linkage to any long-term plans, such as the manufacturing strategy.

It can be concluded that the state-of-art regarding assessment of reconfigurability potential is lacking and that there is a need for an improved connection between the strategy and the current state of the manufacturing system. There is a need for an assessment process which connects the current potential for reconfigurability to the manufacturing strategy of the company, to ensure that the improvements can be aligned 
to the manufacturing strategy and thus, create a favourable direction of the development the manufacturing system.

\subsection{Reconfigurability characteristic}

Reconfigurability is characterised by the ability to adapt the manufacturing capabilities in a timely and cost-efficient manner [29]. The ability for a manufacturing system to be reconfigurable can be broken down to the key characteristics of reconfigurability i.e. customisation, scalability, convertibility, diagnosability, integrability, and modularity [1]. Through the evaluation of the current level of reconfigurability within a manufacturing system the key characteristics could be used to evaluate the manufacturing system [16]. By using the key characteristics of reconfigurability is it possible for the manufacture to see which aspects of the manufacturing system that affects the system's ability to be reconfigurable and thus also, see which aspects that could be improved to gain higher degree of reconfigurability [16].

The key characteristics of reconfigurability is summarised in Table 3 and explained in more detailed in the following sections.

Table 3. Key characteristics of reconfigurability

\begin{tabular}{|c|c|}
\hline Characteristic & Description \\
\hline Customisation & $\begin{array}{l}\text { Customisation refers to the ability to customise the system to be able to produce the } \\
\text { required product family [3]. }\end{array}$ \\
\hline Convertibility & $\begin{array}{l}\text { Convertibility, the ability to easily transform the functionality of existing system and } \\
\text { machines to suit the new manufacturing requirements [20]. }\end{array}$ \\
\hline Scalability & $\begin{array}{l}\text { Scalability refers to the ability of being able to incrementally scale the capacity of the } \\
\text { manufacturing system, both up and down [12]. }\end{array}$ \\
\hline Diagnosability & $\begin{array}{l}\text { Diagnosability it is the ability to quickly identify issues and root causes which } \\
\text { produces defect products and to fast being able to correct the issues causing the product } \\
\text { defects [20]. }\end{array}$ \\
\hline Modularity & $\begin{array}{l}\text { Modularity refers to that the whole system, both software and hardware are designed to } \\
\text { be modular [40]. }\end{array}$ \\
\hline Integrability & $\begin{array}{l}\text { Integrability refers to that the system and its components are designed for current and } \\
\text { future integration with each other and future new technology [40]. }\end{array}$ \\
\hline
\end{tabular}

Customisation refers to the ability to customise the system to be able to produce the required product family and can be seen as the change driver and trigger of reconfigurability [5]. Direct linked to the customisation of the system is convertibility and scalability as they influence the capacity of the system in terms of function and volume [10], [40]. Convertibility and scalability can be related to operational decisions and, thus, also the reconfiguration of the system [5]. Convertibility is the ability to easily transform the functionality of existing system and machines to suit the new manufacturing requirements [40]. While scalability is connected to being able to incrementally change the capacity of the system up and down [10].

Diagnosability is the ability to quickly identify issues and root causes which produces defect products and to fast be able to correct the issues [40]. Diagnosability is connected to both convertibility and scalability, and integrability and modularity, and is connected to both the configuration of the system and the reconfiguration of the system [5].

Modularity and integrability is closely linked together and can be hard to separate, and are both connected to the configuration of the system and is also connected to convertibility, saleability and diagnosability [5]. Modularity refers to that the whole system, both software and hardware are designed to be modular [40]. While integrability 
refers to that the system and its components are designed for current and future integration with each other as well as future technologies [40].

\section{Result}

\subsection{Empirical findings}

The processes that were observed within the four cases where divided into three steps manufacturing candidate identification, assessment of manufacturing candidate, and conceptual solution generation. The case companies' representatives identified manufacturing candidate, i.e. a manufacturing sub system that would benefit of an increased level of reconfigurability. The suitability of the candidates was then evaluated based on the existing challenges and opportunities within the sub system related to each companies' strategies and goals, and how reconfigurability could deal with these challenges. Only one of the cases had explicitly determined reconfigurability as a part of their strategy to improve their manufacturing system to face the increasing uncertainty. The other three cases had, however, also stated that they needed ways of working to better handle the increasing uncertainty. The candidates that were selected varied in character, from a single machine to a whole workstation.

The evaluation tool was based on the key characteristics which had been broken down into assessment criteria which in turn had been further broken down into questions. The questions were answered by the case representatives which were familiar with the selected candidate. During the assessment of the manufacturing candidates discussions were held between the case company representatives. The representatives discussed the manufacturing candidate from different perspectives and backgrounds. It was concluded that the broader competences that the group had the better the possibilities for the assessment. After the assessment were completed the result was analysed by the team. The representatives thought that it was hard to grasp the result of the assessment, even though they could see how their candidate performed in accordance to each of the key characteristics. The result was deemed hard to understand since their current strategy's goals was developed without reconfigurability in mind. It led to that the result was not comparable to any of their existing goals within the case companies. The representatives lacked goals to compare their result with, to know where they should put efforts in improvements and which areas the key characteristics already had a sufficient performance in. It was concluded by the representatives that the result would easier be analysed and interpreted if the goals had been set in beforehand.

After the assessment of the candidate and the analysis of the result, the improvements of the candidate were conceptualised. Again, discussions were held regarding how to interpret the results and what improvements would be beneficial to the reconfigurability of the manufacturing candidate. However, even though the representatives lacked a clear strategy and goals to follow when designing their conceptual solution conceptual solutions with improvements could be developed within all of the cases.

\subsection{Conceptual assessment process}

In the proposed conceptual process, the characteristics are used throughout each of the seven steps as the link between the steps and the process. The process's seven steps are: 
strategy formulation, strategy alignment, identifying manufacturing candidates, evaluate manufacturing candidate, analyse evaluation result, create action plan, and execute action plan. After the seventh step, the process can begin again from the first step, or from the third step if the strategy is deemed to be still relevant. The steps are summarised in Table 4.

Table 4. Conceptual assessment process steps

\begin{tabular}{lc}
\hline$\#$ & Steps \\
\hline 1 & Strategy formulation \\
3 & Strategy alignment, goal formulation \\
4 & Identification of manufacturing candidate \\
5 & Evaluation of manufacturing candidate \\
6 & Analysis of results \\
7 & Creation of action plan \\
\hline
\end{tabular}

The assessment process starts with the formulation of the manufacturing strategy where the reconfigurability focus is a natural part. The strategy embodies the long-term vision for the manufacturing system. Through the manufacturing strategy the management can show which capabilities that are wanted within the manufacturing system to stand better prepared for the ever-changing market demands. However, the strategy needs to be broken down to goals with a shorter time horizon so the organisation easier can move towards the goals. It is important that the management team enables decisions making that facilitate the development and nurture the desired capabilities [41], such as reconfigurability and its underling characteristics. With a good strategy breakdown with goals with variating time horizons (long-term, medium-term, and shortterm) manufacturing firms can be able to start transforming towards reconfigurable manufacturing, one step at the time. These goals could then be connected to the characteristics of reconfigurability to keep the connection from the strategy to the improvement projects being conducted in the manufacturing system.

After the goals have been created the next step is to identify a suitable manufacturing candidate to investigate its current level of reconfigurability. The manufacturing candidate can be selected in many ways such as starting where there already exists demand for variants, or where there is an increased strategic importance for the manufacturing system to be high performing.

Thereafter, an assessment of the manufacturing candidate in order to evaluate the existing level of reconfigurability.

The result from the assessment should then be analysed in regard to the goals that have been created. By going back to the assessment criteria and the questions it is possible to further pinpoint what aspects of the manufacturing candidate that has improvement potential.

Based on the identified improvement areas, an action plan is constructed describing how the manufacturing system could be improved. The improvements could be of different character, such as creation of a standard machine interface to be applied on all machines or design of reconfigurable solutions within a section. The action plan drives implementation of improvements and, thus, step wise actions towards reconfigurable.

The final step of the process is the execution of the action plan to where the improvement is implemented to the system. When the improvement is implemented the process can start over again, either from the beginning if it has been a major improvement, 
or from the identification of a new manufacturing candidate. There can be multiple improvement cycles running, i.e. step 3-7, at the same time.

The tentative assessment process can be described as two cyclical phases, first, step 1 and 2, followed by step 3-7 from Table 4, the process is illustrated in Figure 1.

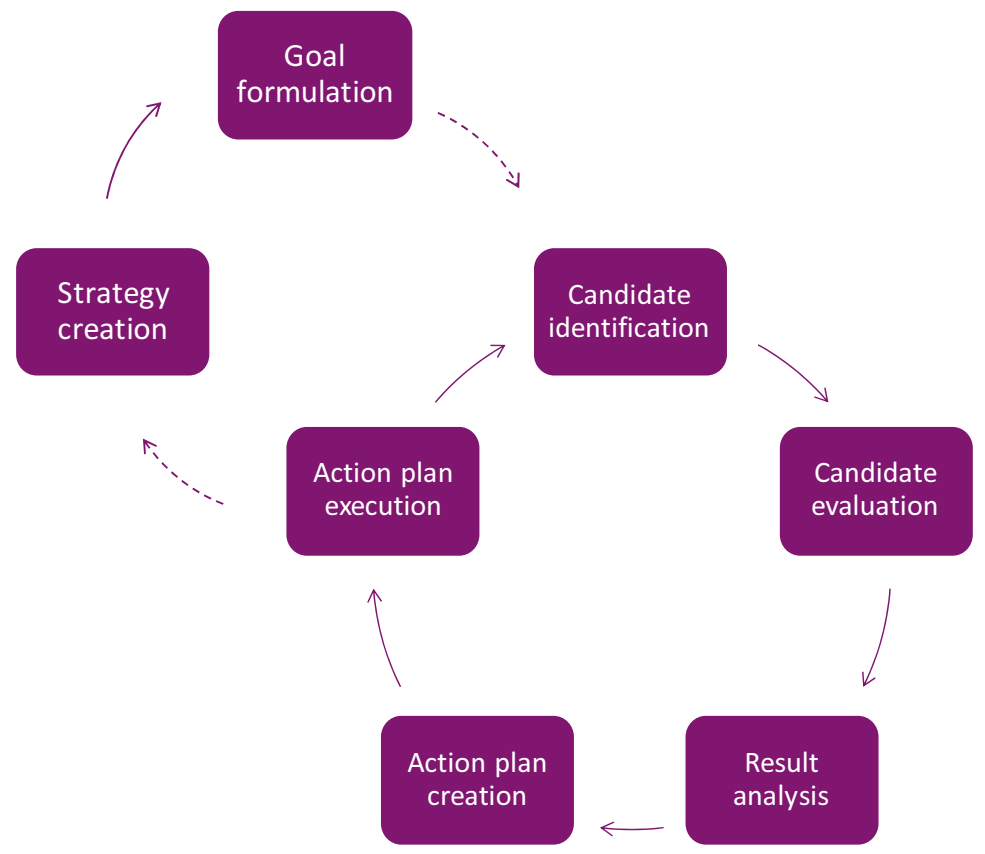

Figure 1. Conceptual assessment process.

The goal of the assessment process is to identify the level of reconfigurability potential within the manufacturing system and find areas for improvement. To connect the current level of reconfigurability in the manufacturing system and the wanted future state, the company manufacturing strategy should be used together with the key characteristics.

The conceptual assessment process addresses the three identified gaps, i.e. lack of connection to strategy, (2) lack of predefined goals for reconfigurability, and (3) the difficulty in interpreting the result of the analysis. By combining the evaluation process and the strategy creation and goal formulation the evaluators have the predefined goals, values and metrics connected to the reconfigurability level and its key characteristics the to compare their evaluation result with making the analysis easier. With an easier analysis the action plan can become easier to create, and then achieve the intended output of the improvement.

The conceptual assessment process shows a way of how an existing manufacturing system reconfigurability potential could be assessed, which answers RQ 2, as well as it provides a way for connecting manufacturing strategy and the manufacturing system current reconfigurability potential. 


\section{Conclusions}

The purpose of this paper was to increase the knowledge of the transformation towards reconfigurable manufacturing systems in a brownfield context by development of a conceptual assessment process. Through a literature review were the current available assessment tools identified and classified into four different categories, (1) Configuration evaluation, (2) Element evaluation, (3) Pre-design evaluation, and (4) Potential evaluation. It was found that there were only two tools available which evaluated the potential for reconfigurability, one of the tools were a continuation of the other tool.

Based on the process of assessing the current level of reconfigurability within a manufacturing system through the application of the assessment tool by [21] in a multiple case study. Three main gaps were found through the multiple case study, (1) lack of connection to strategy, (2) lack of predefined goals for reconfigurability, and (3) the difficulty in interpreting the result of the analysis. An assessment process was conceptualised to address these three gaps. The reconfigurable assessment process consists of seven steps, i.e. strategy formulation, strategy alignment, identifying manufacturing candidates, evaluate manufacturing candidate, analyse evaluation result, create action plan, and execute action plan. The process is centred around the characteristics of reconfigurability linking the manufacturing strategy and its goals to the assessment of the existing manufacturing system.

The process incorporates a learning activity based on assessment criteria, questions and design guidelines for one and each of the reconfigurability characteristic, which enables the manufacture to further increase their understanding of reconfigurability and how it could be achieved.

Future research is needed to increase the knowledge in how strategies and goals can enable reconfigurable manufacturing improvements in a brownfield context. Measurements for the key characteristics are also required to be furthered investigated, to find an easily used and accurate setup of measurements. The assessment result analysis also needs to be further developed to create an effective way of identifying improvement areas to increase the reconfigurability level within the manufacturing system.

\section{References}

[1] Y. Koren et al., "Reconfigurable Manufacturing Systems," CIRP Ann., vol. 48, no. 2, pp. 527-540, 1999.

[2] A.-L. Andersen, J. K. Larsen, T. D. Brunoe, K. Nielsen, and C. Ketelsen, "Critical enablers of changeable and reconfigurable manufacturing and their industrial implementation," J. Manuf. Technol. Manag., vol. 29 , no. 6, pp. 983-1002, Oct. 2018.

[3] H. ElMaraghy and H.-P. Wiendahl, "Changeable Manufacturing," in CIRP Encyclopedia of Production Engineering, Berlin, Heidelberg: Springer Berlin Heidelberg, 2019, pp. 219-226.

[4] H.-P. Wiendahl et al., "Changeable Manufacturing - Classification, Design and Operation," CIRP Ann. Manuf. Technol., 2007.

[5] A. Napoleone, A. Pozzetti, and M. Macchi, "A framework to manage reconfigurability in manufacturing," Int. J. Prod. Res., vol. 56, no. 11, pp. 3815-3837, Jun. 2018.

[6] A. Napoleone, A. Pozzetti, and M. Macchi, "Core Characteristics of Reconfigurability and their Influencing Elements," IFAC-PapersOnLine, vol. 51, no. 11, pp. 116-121, 2018.

[7] M. R. Abdi and A. W. Labib, "A design strategy for reconfigurable manufacturing systems (RMSs) using analytical hierarchical process (AHP): A case study," Int. J. Prod. Res., vol. 41, no. 10, pp. 2273-2299, Jan. 2003.

[8] A.-L. Andersen, T. D. Brunoe, K. Nielsen, and C. Rösiö, "Towards a generic design method for reconfigurable manufacturing systems," J. Manuf. Syst., vol. 42, pp. 179-195, Jan. 2017. 
[9] D. G. H. Sorensen, T. D. Brunoe, and K. Nielsen, "Brownfield Development of Platforms for Changeable Manufacturing," Procedia CIRP, vol. 81, pp. 986-991, 2019.

[10] H. ElMaraghy, "Flexible and reconfigurable manufacturing systems paradigms," Int. J. Flex. Manuf. Syst., vol. 17 , no. 4 , pp. 261-276, Oct. 2005.

[11] C. Rösiö and J. Bruch, "Exploring the design process of reconfigurable industrial production systems," Journal of Manufacturing Technology Management, vol. 29, no. 1. pp. 85-103, 2018.

[12] L. Krantz and A. Thomason, Strategic Investment Decisions: Harnessing opportunites, manageing risks. Pearson Education Limited, 1999.

[13] B. Almannai, R. Greenough, and J. Kay, "A decision support tool based on QFD and FMEA for the selection of manufacturing automation technologies," Robot. Comput. Integr. Manuf., vol. 24, no. 4, pp. 501-507, 2008.

[14] A. M. Farid and D. C. McFarlane, "A TOOL FOR ASSESSING RECONFIGURABILITY OF DISTRIBUTED MANUFACTURING SYSTEMS,” in IFAC Proceedings Volumes, 2006, vol. 39, no. 3, pp. 523-528.

[15] J. D. Ford, L. W. Ford, and A. D'Amelio, "Resistance to Change: The Rest of the Story," Acad. Manag. Rev., vol. 33, no. 2, pp. 362-377, Apr. 2008.

[16] K. Gumasta, S. Kumar Gupta, L. Benyoucef, and M. K. Tiwari, "Developing a reconfigurability index using multi-attribute utility theory," Int. J. Prod. Res., vol. 49, no. 6, pp. 1669-1683, Mar. 2011.

[17] K. K. Mittal and P. K. Jain, "An overview of performance measures in reconfigurable manufacturing system,” in Procedia Engineering, 2014, vol. 69, pp. 1125-1129.

[18] L. N. Pattanaik, R. Kant, and A. Anand, "A FUZZY-BASED NEED ASSESSMENT MODEL FOR RECONFIGURABLE MANUFACTURING SYSTEM,” J. Manuf. Technol. Res., vol. 7, no. 3-4, pp. 163-173, 2015.

[19] R. K. Singh, N. Khilwani, and M. K. Tiwari, "Justification for the selection of a reconfigurable manufacturing system: a fuzzy analytical hierarchy based approach,” Int. J. Prod. Res., vol. 45, no. 14, pp. 3165-3190, Jul. 2007.

[20] A. Booth, D. Papaioannou, and A. Sutton, Systematic Approaches to a Successful Literature Review, 2nd ed. London: Sage Publication Ltd., 2016.

[21] A. Bergström and L. Jödicke, "Reconfigurability Assessment Model," Jönköping University, School of Engineering, 2019.

[22] R. K. Yin, Case Study Research and Applications. Sage Publication Ltd., 2018.

[23] D. Prasad and S. C. Jayswal, "Assessment of a reconfigurable manufacturing system," Benchmarking, 2019.

[24] A.-L. Andersen, T. D. Brunoe, K. Nielsen, and M. Bejlegaard, "Evaluating the investment feasibility and industrial implementation of changeable and reconfigurable manufacturing concepts," J. Manuf. Technol. Manag., vol. 29, no. 3, pp. 449-477, Apr. 2018.

[25] H. Haddou Benderbal, M. Dahane, and L. Benyoucef, "Modularity assessment in reconfigurable manufacturing system (RMS) design: an Archived Multi-Objective Simulated Annealing-based approach,” Int. J. Adv. Manuf. Technol., vol. 94, no. 1-4, pp. 729-749, 2018.

[26] J. M. Park, "Improved methodology for RMS adaptability evaluation," Int. J. Precis. Eng. Manuf., vol. 18, no. 11, pp. 1537-1546, 2017.

[27] I. Eguía, G. Villa, and S. Lozano, "Efficiency Assessment of Reconfigurable Manufacturing Systems," in Procedia Manufacturing, 2017, vol. 11, no. June, pp. 1027-1034.

[28] R. J. Urbanic and R. W. Hedrick, "A matrix-based framework for assessing machine tool reconfiguration alternatives,” Int. J. Adv. Manuf. Technol., vol. 81, no. 9-12, pp. 1893-1919, 2015.

[29] A. M. Farid, "Facilitating ease of system reconfiguration through measures of manufacturing modularity," in Proceedings of the Institution of Mechanical Engineers, Part B: Journal of Engineering Manufacture, 2008, vol. 222, no. 10, pp. 1275-1288.

[30] A. M. A. Youssef and H. ElMaraghy, "Assessment of manufacturing systems reconfiguration smoothness," Int. J. Adv. Manuf. Technol., vol. 30, no. 1-2, pp. 174-193, 2006.

[31] P. Bellini, M. Buonopane, and P. Nesi, "Assessment of a flexible architecture for distributed control," Program. Comput. Softw., vol. 29, no. 3, pp. 147-160, 2003.

[32] G. X. Wang, S. H. Huang, Y. Yan, and J. J. Du, "Reconfiguration schemes evaluation based on preference ranking of key characteristics of reconfigurable manufacturing systems," Int. J. Adv. Manuf. Technol., 2017.

[33] E. Puik, D. Telgen, L. van Moergestel, and D. Ceglarek, "Assessment of reconfiguration schemes for Reconfigurable Manufacturing Systems based on resources and lead time," Robot. Comput. Integr. Manuf., vol. 43, pp. 30-38, 2017.

[34] M. R. Abdi and A. W. Labib, "Feasibility study of the tactical design justification for reconfigurable manufacturing systems using the fuzzy analytical hierarchical process," Int. J. Prod. Res., vol. 42, no. 15, pp. 3055-3076, Aug. 2004. 
[35] C. Rösiö, T. Aslam, K. B. Srikanth, and S. Shetty, "Towards an assessment criterion of reconfigurable manufacturing systems within the automotive industry," in Procedia Manufacturing, 2019.

[36] G. Schuh et al., "Assessment of the scale-scope dilemma in production systems: An integrative approach," Prod. Eng., vol. 5, no. 4, pp. 341-350, 2011.

[37] A. M. Farid and D. C. McFarlane, "Production degrees of freedom as manufacturing system reconfiguration potential measures," in Proceedings of the Institution of Mechanical Engineers, Part B: Journal of Engineering Manufacture, 2008, vol. 222, no. 10, pp. 1301-1314.

[38] A. M. Farid and D. C. McFarlane, "An approach to the application of the design structure matrix for assessing reconfigurability of distributed manufacturing systems," in Proceedings - DIS 2006: IEEE Workshop on Distributed Intelligent Systems - Collective Intelligence and Its Applications, 2006, pp. 121-126.

[39] A.-L. Andersen, T. D. Brunoe, K. Nielsen, and M. Bejlegaard, "Evaluating the investment feasibility and industrial implementation of changeable and reconfigurable manufacturing concepts," J. Manuf. Technol. Manag., vol. 29, no. 3, pp. 449-477, 2018.

[40] M. G. Mehrabi, A. G. Ulsoy, and Y. Koren, "Reconfigurable manufacturing systems: Key to future manufacturing," J. Intell. Manuf., vol. 11, no. 4, pp. 403-419, 2000.

[41] M. Schlickel, Strategy Deployment in Business Units. Berlin, Heidelberg: Springer Berlin Heidelberg, 2013. 